\title{
THE DESIGN OF A SIGNAL CONDITIONING \& ACQUISITION ELEMENTS OF A CHOPPED BROADBAND RADIATION PYROMETER
}

\author{
Kufre Esenowo Jack ${ }^{1}$, Israel Etu ${ }^{2}$, Veronica Nicholas Ukanide ${ }^{3}$ \\ ${ }^{I}$ Department of Electrical /Electronic Engineering Technology, Akanu Ibiam Federal Polytechnic,Unwana, P.M.B \\ 1007 Afikpo, Ebonyi State \\ ${ }^{2}$ Department of Electrical /Electronic Engineering Technology, Akanu Ibiam Federal Polytechnic,Unwana, P.M.B \\ 1007 Afikpo, Ebonyi State \\ ${ }^{3}$ Department of Electrical /Electronic Engineering Technology, Akanu Ibiam Federal Polytechnic,Unwana, P.M.B \\ 1007 Afikpo, Ebonyi State
}

\begin{abstract}
This paper presents the design of signal conditioning and acquisition elements of a chopped broadband radiation pyrometer. This instrument is capable of measuring temperature between $900^{\circ} \mathrm{C}$ and $1200^{\circ} \mathrm{C}$. This work aims at solving the problem of measuring hot objects with a thermometer. The radiation pyrometer is a non-contact temperature sensor that infers the temperature of an object by detecting its naturally emitted thermal radiation. It collects the visible and infrared energy and focuses it on a detector. The detector used in this device is a thermal sensor. It receives heat energy reflected from a mirror inclined at $45^{\circ}$ to the incident signal from the hot object. The design achieved the following: temperature range measured, from $900^{\circ} \mathrm{C}$ to $1200^{\circ} \mathrm{C}$; the calibrated instrument is fairly linear with a tolerable non-linearity of $3.6 \%$, with the sensitivity of $0.014 V^{\circ} \mathrm{C}^{-1}$, the resolution was quite very small as such it can easily detect the slightest change at its input; the rotating shutter was configured to supply the chopped signal; it operates at a frequency of $50 \mathrm{~Hz}$ that is lower than the system frequency of $200 \mathrm{~Hz}$; the data acquisition system was able to capture data at a periodic time of 0.02 second and below, the system operates within the specified sampling range thus, satisfying Nyquist criteria. The signal so received by the detector is translated to a human readable form and sent to a display.
\end{abstract}

Keywords:- Broadband Radiation Pyrometer, Temperature Sensor, Instrument, Chopped and Detector.

\section{INTRODUCTION}

The broadband radiation pyrometer will be used to measure a temperature without making contact with the object. Thermal sensors detect the temperature of the environment and the objects in it. This instrument is designed in such a way that the sensor would get the radiated signal from the source (Thomas, 2006). Other means of measuring high temperature include the use of narrow band radiation pyrometer and broadband (un-chopped) radiation pyrometer (Alan, 2001). All these instruments operate on the same principle except that the chopped broadband radiation pyrometer has a unique feature. This feature is a mechanical shutter that closes and opens the gate to the detector intermittently to prevent it from being burnt due to high temperature (Bentley, 2005). In practice, other traditional radiation pyrometers give error temperature readings due to the actual surface condition of the object, the effect of oxidation and coating of the black body (Ramos et al., 2012). The application of a radiation pyrometer for temperature measurement in other relevant areas with the range covering 250 to $600^{\circ} \mathrm{C}$ were found in aluminum processing according to Jones et al., (1987). Muller et al., (2001) developed a two-color pyrometer used in measuring the temperature of surfaces with unknown emissivity during high-speed turning processes. Moreover, the accuracy of the two-color pyrometer was compared with the accuracy of monochromatic pyrometers for different metallic surfaces. Similarly, the rolling and extrusion demonstrate how much greater uncertainties that result from the various factors affect emissivity (Jones et al., 1987). Quantum Logic Corporation has developed, patented and currently, marketed Laser and Microcomputer Pyrometers, usually employ a new technology with small semiconductor lasers and microcomputers for the purpose of determining the spectral emissivity from a distance. As a result this measurement of the emitted radiation, the microcomputer can compute the actual temperature of the body with Planck Equation (Webster, 1999). The accuracy of the temperature measurement is usually higher than that of the primarily known pyrometers. Industrial and research applications reveal that, it is safer to measure the temperature of a body from a distance without touching it. Evidently, when something is moving, when it is hot (as inside a furnace) or when it is difficult to access, the best option is a non-contact thermometer (Orlov et al., 2014). This device can measure a wide range of the heat radiating from a body. This is why the term, broadband is used for it. Pyrometers measure the temperature of bodies, integrating the infrared energy coming from them. In general, measuring temperature using infrared techniques is more complicated than using contact sensors due to the existence of problems associated with the 
physical measurement procedure. The main purpose for improving pyrometers is to increase the measurement accuracy by reducing the influence of background temperature of the optical system. The issue with conditioning the information so acquired, is the main reason this design was embarked upon.

\section{RELATED LITERATURES}

Radiation Thermometry has been a practice for some years. The first practical infrared thermometer was the human eye. Research shows that the human eye has a lens that directs radiation to the retina. The retina is in turn, stimulated thereby transferring the signal to the brain. The brain then serves as the indicator of the radiation by converting the signal to a measure of temperature, if well calibrated (Komanduri \& Hou, 2001). The word, pyrometer is from the Greek root pyro, meaning fire. At first, it was used to indicate a device that can measure temperatures of objects beyond the incandescent level (objects bright to the human Eye). Infrared heat has been useful for many years. A Study shows that many years ago, the sun was used to heat objects form molds for construction (Bowden et al., 1954). Craftsmen knew how hot to make metals before they could form them. This was achieved by the experience of the color of iron. Due to the scarcity of fuel for firing, olden-day builders depended on the infrared radiation of the sun to dry the bricks for their buildings.

The common applications of radiation thermometry are the heat treating, forming, tempering and annealing of glass. Others are the casting, rolling, forging, and heat treating of metals; as well as quality control in the food, pulp, and paper industry. Furthermore, it includes the drying of plastics, extrusion, lamination of rubber and paper, and in the curing process of paints, resins, and adhesives. Nontouch temperature sensors are invaluable research tools in military, medical, industrial, meteorological, ecological, forestry, agriculture, and chemical implementations.

The first license for a radiation thermometer was issued in 1901. The device made use of a thermoelectric sensor. It used an electrical output signal and exhibited self-operation. In 1931, the first commercially-available total radiation thermometers were introduced. These devices were widely used throughout industries to record and control industrial processes. They are still used today, but mainly used for low-temperature applications. The first modern radiation thermometers came into being after the Second World War originally developed for military use; and has since then undergone modifications until today when it has metamorphosed to radiation pyrometers.

\section{DESIGN TASK AND MODEL}

This work aims at designing signal conditioning and acquisition elements of a chopped broadband radiation pyrometer that is capable of measuring temperature from $900^{\circ} \mathrm{C}$ to $1200^{\circ} \mathrm{C}$
The objectives of this work are to:

i. Design a thermal detector which can convert incident radiant power into an electrical output.

ii. Design a signal conditioning element that can handle the output of the thermal detector to a form more suitable for further processing.

iii. Design a data acquisition element of the pyrometer.

iv. Choose a suitable chopping frequency that matches the physical properties of the system under design.

v. Estimate the limits imposed by the chosen hardware on overall system resolution.

vi. Provide the calibration data and plot the output voltage against the source temperature.

\section{THE DESIGN PARAMETERS}

i. The Thermal Detector Data

The sensing element of the pyrometer under review will make use of the following physical properties:

Heat transfer coefficient $U=2 \times 10^{4} \mathrm{Wm}^{-2}{ }^{o} \mathrm{C}^{-1}$

Surface area $A=1.6 \times 10^{-4} \mathrm{~m}^{2}$

Heat capacity and Mass of the detector $M C=1.6 \times 10^{-2} \mathrm{~J}^{o} \mathrm{C}^{-1}$

Temperature Coefficient of Resistance $\alpha=0.004^{\circ} C^{-1}$

Reference Resistance $R_{o}=100 \Omega$. at $0^{\circ} \mathrm{C}$

The assumed rate at which radiant energy falls on the thermal detector is $50 \mathrm{~T}^{4} \mathrm{pWcm}^{-2}$

ii. The Digital Signal

Frequency of $10 \mathrm{kHz}$

ADC with 12bits

Voltage range of \pm 1 volt

iii. Design Temperature

Range $\quad 900^{\circ} \mathrm{C}$ to $1200^{\circ} \mathrm{C}$

Environment temperature $25^{\circ} \mathrm{C}$

iv. The Bolometer Design

Voltage 3.0volts

5. THE DESIGN OF THE BROAD BAND CHOPPED PYROMETER

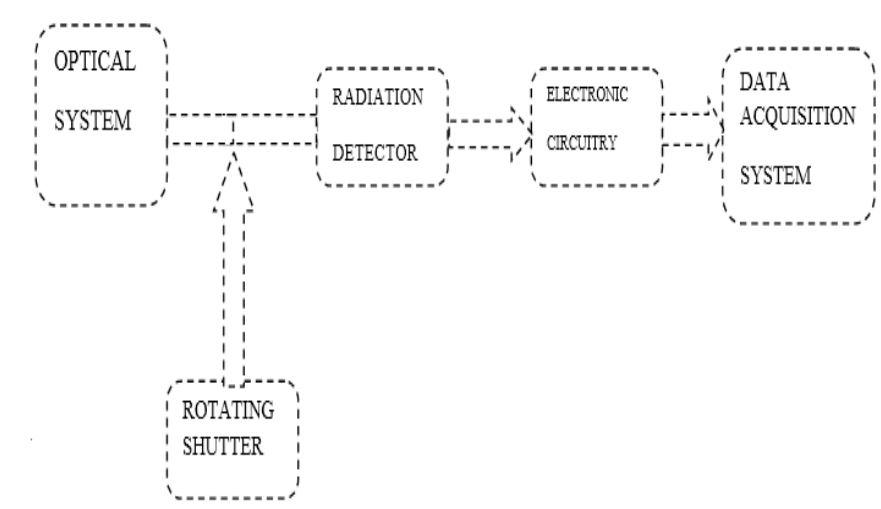

Fig 1 The block representation of the designed broad band chopped pyrometer 
The Broad band chopped pyrometer in its design considers five different operational units:

i. Optical System: This is the unit that collects the visible and infrared energy from an object and focuses it directly on a detector.

ii. Radiation Detector: This is the device that converts the incident energy into an electrical signal to drive a temperature display unit.

iii. The Electronic Circuitry: This consists of the following sub-circuits: Bridge Circuit, Amplifier, Level Shifter, Analogue-to-Digital Converter (ADC) and Signal Conditioning Circuits.

iv. Data Acquisition System: The data acquisition system displays the temperature detected and translates what each data represents.

v. Rotating Shutter: The rotary mechanical shutter system will periodically interrupt the radiation from reaching the detector to save it from burning.

\section{THE SYSTEM DESIGN AND MODELLING}

\subsection{The Mathematical Design Modelling}

The system design and the related models were carried out in stages.

Stage 1: Mechanical Rotating Shutter Design

The total radiation released per unit surface area of a black body according to Stefan-Boltzmann law,

$$
E=K T^{4}\left(W m^{-2} K^{4}\right)
$$

Where,

$T$ is the absolute temperature of the body

$K$ is a constant of radiation that depends on the heat intensity, the nature of heat spectrum and the kind of material of the body.

The time constant and chopping frequency of the thermal detector governs the speed of the mechanical rotating shutter. The time constant is given by

$$
\tau=\frac{M C}{U A}
$$

Where,

$\tau$ is the Time constant

$\mathrm{M}$ is the Mass of the detector $(\mathrm{kg})$

$\mathrm{C}$ is the specific heat capacity of the detector $\left(\mathrm{J} \mathrm{kg}^{-10} \mathrm{C}^{-1}\right)$

A is the area of the detector $\left(\mathrm{m}^{2}\right)$

$\mathrm{U}$ is the Heat transfer coefficient $\left(\mathrm{Wm}^{-20} \mathrm{C}^{-1}\right)$

Chopping frequency of the rotating shutter is given by

$$
f_{c}=\frac{1}{2 \pi \tau}
$$

Stage 2: The Thermal Detector

The incident power $P_{D}(W)$ would heat the thermal detector to a temperature $\mathrm{T}_{\mathrm{D}}\left({ }^{\circ} \mathrm{C}\right)$ which is usually above the surrounding temperature $\mathrm{T}_{\mathrm{S}}\left({ }^{\circ} \mathrm{C}\right)$ (Bentley, 2005).

The heat balance equation for the detector is given by:

[Power incident on the detector] - [Power conducted away from detector $]=[$ Power absorbed by the detector $]$

Mathematically the above expression is given by:

$$
P_{D}=U A\left(T_{D}-T_{S}\right)=M c \frac{d T_{D}}{d t}
$$

Where,

$\mathrm{P}_{\mathrm{D}}$ is the total Incident of the detector

$\mathrm{U}$ is the Heat transfer coefficient

$\mathrm{A}$ is the area of the detector

$\mathrm{M}$ is the mass of the detector

$\mathrm{C}$ is the specific heat capacity of the detector

$T_{D}$ is the Detector temperature

$\mathrm{T}_{\mathrm{S}}$ is the temperature of the surrounding

Putting the time constant of the detector [equation (2)] above, into equation (5), it reduces to:

$$
T_{D}+\tau \frac{d T_{D}}{d t}=\frac{1}{U A} P_{D}+T_{s}
$$

In the steady state mode, $\frac{\mathrm{dT}_{\mathrm{D}}}{\mathrm{dt}}=0$ which further reduces equation (5) to:

$$
T_{D}=\frac{P_{D}+T_{s}}{U A}
$$

Where $T_{D}$ is proportional to $P_{D}$ (rate of heat influx) and inversely proportional to UA that is the rate at which heat is lost.

Equation (6) thus establishes a relationship that gives an intercept of $T_{S}$ and a gradient that is same as the inverse of the terms $U A$ when presented graphically.

Stage 3: Bolometer Design

For this design, a Bolometer (a passive resistive device) in a form of a bridge circuit is used as the thermal detector. 


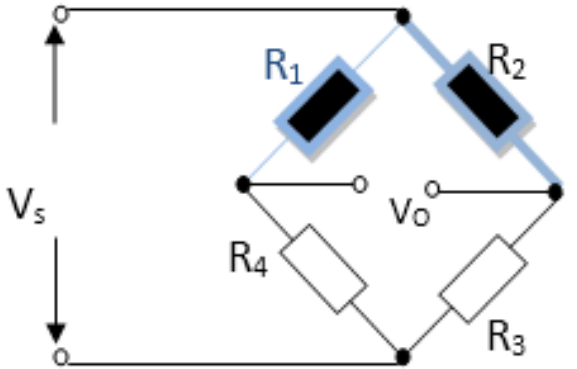

Fig 2 Bridge circuit of a bolometer (sensor)

$\mathrm{R}_{1}$ is the radiation-detecting (or measuring) element at $\mathrm{T}_{\mathrm{D}}\left({ }^{\circ} \mathrm{C}\right)$ and is given by,

$$
\mathrm{R}_{1}=\mathrm{R}_{0}\left(1+\alpha \mathrm{T}_{\mathrm{D}}\right) \text {, the detector resistance. }
$$

$\mathrm{R}_{2}$ is the reference element at $\mathrm{T}_{\mathrm{S}}\left({ }^{\circ} \mathrm{C}\right)$ and is given by,

$$
\mathrm{R}_{2}=\mathrm{R}_{0}\left(1+\alpha \mathrm{T}_{\mathrm{S}}\right), \text { the reference resistance. }
$$

The two resistors $R_{3}$ and $R_{4}$ are fixed equal resistors. $R=R_{4}=R_{3}$

Where $\mathrm{R}_{0}$ is the internal resistance of the (sensor) Bolometer at $0^{\circ} \mathrm{C}$; and $\alpha$ is the temperature coefficient of resistance.

The approximated output of the Bolometer bridge circuit is given by,

$$
\begin{gathered}
V_{0}=V_{S}\left\{\frac{R_{0}\left(1+\alpha T_{D}\right)}{R+R_{0}\left(1+\alpha T_{D}\right)}-\frac{R_{0}\left(1+\alpha T_{S}\right)}{R+R_{0}\left(1+\alpha T_{S}\right)}\right\} \\
V_{0}=0 \text { for } T_{\mathrm{D}}-T_{\mathrm{S}}
\end{gathered}
$$

Rearranging this expression from equation (9) will give:

$$
V_{0}=V_{S}\left\{\frac{1}{1+\frac{R 1}{R_{0}\left(1+\alpha T_{D}\right)}}-\frac{1}{1+\frac{R 1}{R_{0}\left(1+\alpha T_{S}\right)}}\right\}
$$

By setting $R \gg R_{0}$ the output can be linearized at the expense of a smaller sensitivity.

In this limit the output becomes

$$
V_{0} \approx V_{S}\left\{\frac{\left(1+\alpha T_{D}\right)}{R / R_{0}}-\frac{\left(1+\alpha T_{S}\right)}{R / R_{0}}\right\}
$$

Which simplifies to $V_{0} \approx V_{S} \alpha \frac{R_{0}}{R}\left(T_{D}-T_{S}\right)$

The output of the bolometer becomes $V_{o}=V_{s} \frac{R_{0}}{R} \alpha\left(T_{D}-T_{s}\right)$

Equation (10) above represents the output from the Bolometer. The output is an AC voltage since a rotating shutter was incorporated in the pyrometer.

The output is then fed into the amplifier as an input for signal conditioning.

Stage 4: The Design and modelling of an Analogue Amplifier with a level shifter as a signal conditioning measure.

In this step, A.C. signals are generated as a result of the chopping effect of the rotating shutter that requires further amplification to enhance effective digitization with a minimum aliasing. An operational amplifier with a level shutter is added as illustrated in figure 3 .

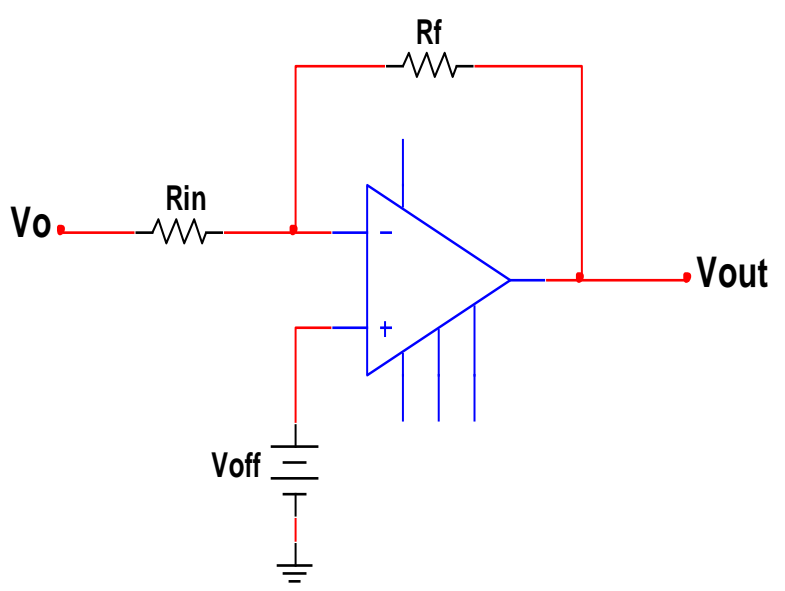

Fig 3 Diagram of an inverting amplifier for signal conditioning

From the circuit diagram of the inverting amplifier in figure 3 , an offset voltage for adjusting the output of the amplifier was modelled in series with one of the amplifier input terminals. The offset voltage is placed in the positive input terminal. The output voltage equation of the inverting amplifier is given by

$$
V_{\text {out }}=-V_{o} \frac{R_{f}}{R_{\text {in }}}+\left(1+\frac{R_{f}}{R_{\text {in }}}\right) \times V_{o f f}
$$

Similarly, equation (11) can be expressed as:

$$
V_{o}=-V s \frac{R_{f}}{R_{i n}}+\left(1+\frac{R_{f}}{R_{i n}}\right) \times V_{o f f}
$$


$V_{\text {out }}=-\frac{R_{f}}{R_{\text {in }}}\left(1.2^{-4} \times\left(T_{S}-T_{D}\right)\right)+\left(1+\frac{R_{f}}{R_{i}}\right) V_{\text {off }}$

Where $V_{0}$ is the input voltage (output of the thermal detector), $\frac{R_{f}}{R_{\text {in }}}$ is the Gain of the amplifier and $\mathrm{V}_{\text {off }}$ is the offset voltage.

The output voltage of the amplifier, $\mathrm{V}_{\text {out }}$ is of the range $\pm 1 \mathrm{~V}$ that should correspond to the given temperature range of $900^{\circ} \mathrm{C}$ to $1200^{\circ} \mathrm{C}$ (or $1173^{\circ} \mathrm{K}$ to $1473^{\circ} \mathrm{K}$ ).

Now, let the $\mathrm{V}_{\text {off }}=0$, at the initial temperature of $900^{\circ} \mathrm{C}$ $\left(1173^{\circ} \mathrm{K}\right)$. The range of temperature defined for the Pyrometer calibration is selected for an interval of $10^{\circ} \mathrm{C}$ difference from $900^{\circ} \mathrm{C}$ completing a total of 31 calibrations for the enhancement of accuracy and system precision. Similarly, from the earlier computation that was demonstrated it indicates that the mid-range value of $\left(T_{S}-T_{D}\right)$ was obtained at an absolute temperature of $76.59 \mathrm{~K}$.

Hence, at $\left(T_{S}-T_{D}\right)=-76.59 K, V_{O}=0$; as stated. Putting this into available output voltage in equation (12) $-1 \mathrm{~V}$.

Step 5: Signal Processing Using Analog-To-Digital Converter (ADC)

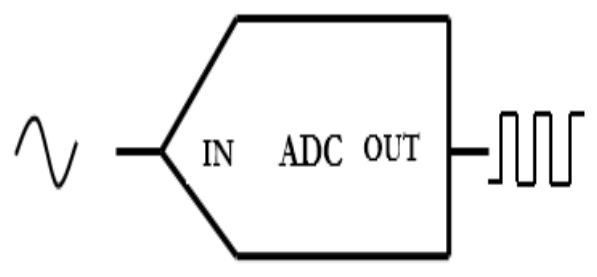

Fig 4 Analogue-to-Digital Converter circuit

The Analogue-To-Digital Converter circuit in figure 4 consists of an electronic circuit component that converts a continuous quantity to a discrete time signal. Its resolution indicates the number of discrete values produced. Resolution is usually expressed in bits. The resolution, Q of the ADC are equal to the least significant bit (LSB) voltage. According to this design specification and parameter adopted, the voltage amplitude of the analog signal voltage amplitude range is $10 \mathrm{KHz}, 12$ bits with \pm 1 volt. The quantized signal level was determined by: Quantization level $=\frac{\Delta V}{2}=\frac{+1-(-1)}{2}=\frac{2}{2}=1.0 \mathrm{~V}$

The resolution $\mathrm{Q}$ of the ADC is denoted by the first least significant bit (LSB) and given by:

$$
Q=\frac{2 A}{2^{n}}=\frac{A}{2^{n-1}}
$$

A is the peak-to-peak amplitude of the analogue signals. Hence;

$$
Q=\frac{+1-(-1)}{2^{12-1}}=\frac{2}{2^{11}}=\frac{2}{2048}=9.765625 \times 10^{-4} \mathrm{~V}
$$

Stage 6: Data Acquisition System

Here the output of the design is displayed as the last section of the block diagram for the design actualization. The implementation of this section is by running a suitable computer program or relevant design to enable the data acquisition process having set the speed of the rotating shutter; such rate should slightly $\geq 50 \mathrm{~Hz}$ at all times. At a speed rate of $50 \mathrm{~Hz}$, the data acquisition processing speed should be $\geq 50 \mathrm{~Hz}$ at a period $\leq 0.02$ second, so that data can be acquired within the specified range.

\section{RESULTS AND ANALYSIS}

Design Parameters for Broadband Pyrometer Calibration $\alpha=0.004^{\circ} \mathrm{C}^{-1} ; T_{S}=298 \mathrm{~K} ; V_{S}=3.0 \mathrm{~V} ; V_{\text {ref }}=-9.1725 \times$ $10^{-3} \mathrm{~V}$

$\mathrm{R}=100 \mathrm{~K} \Omega ; \quad R_{O}=1 \mathrm{~K} \Omega ; \quad R_{O} / R=0.01 ; \quad R_{f}=5 K \Omega ; R_{i}=$ $10 \Omega ; R_{f} / R_{i}=500$

Table 1: Results of the Design for the Broadband Pyrometer Calibration

\begin{tabular}{|l|l|l|l|l|l|l|l|}
\hline & TEMP $\left[{ }^{\circ} \mathbf{C}\right]$ & $\mathbf{T E M}[\mathbf{K}]$ & $\boldsymbol{P}_{\boldsymbol{D}}[\mathbf{W}]$ & $\boldsymbol{T}_{\boldsymbol{D}}[\mathbf{K}]$ & $\left(\boldsymbol{T}_{\boldsymbol{S}}-\boldsymbol{T}_{\boldsymbol{D}}\right)[\mathbf{K}]$ & $\boldsymbol{V}_{\boldsymbol{O}}[\mathbf{V}]$ & $\boldsymbol{V}_{\text {ouT }}[\mathbf{V}]$ \\
\hline 1. & 900 & 1173 & 151.46 & 345.33 & -47.33 & -0.006 & -1.756 \\
\hline 2. & 910 & 1183 & 156.69 & 346.97 & -48.97 & -0.006 & -1.657 \\
\hline 3. & 920 & 1193 & 162.05 & 348.64 & -50.64 & -0.006 & -1.557 \\
\hline 4. & 930 & 1203 & 167.55 & 350.36 & -52.36 & -0.006 & -1.454 \\
\hline 5. & 940 & 1213 & 173.20 & 352.13 & -54.13 & -0.006 & -1.348 \\
\hline 6. & 950 & 1223 & 178.98 & 353.93 & -55.93 & -0.007 & -1.240 \\
\hline 7. & 960 & 1233 & 184.90 & 355.78 & -57.78 & -0.007 & -1.129 \\
\hline 8. & 970 & 1243 & 190.98 & 357.68 & -59.68 & -0.007 & -1.015 \\
\hline 9. & 980 & 1253 & 197.20 & 359.63 & -61.63 & -0.007 & -0.898 \\
\hline
\end{tabular}




\begin{tabular}{|l|l|l|l|l|l|l|l|}
\hline 10. & 990 & 1263 & 203.57 & 361.62 & -63.62 & -0.008 & -0.778 \\
\hline 11. & 1000 & 1273 & 210.09 & 363.65 & -65.65 & -0.008 & -0.656 \\
\hline 12. & 1010 & 1283 & 216.77 & 365.74 & -67.74 & -0.008 & -0.531 \\
\hline 13. & 1020 & 1293 & 223.61 & 367.88 & -69.88 & -0.008 & -0.403 \\
\hline 14. & 1030 & 1303 & 230.61 & 370.07 & -72.07 & -0.009 & -0.271 \\
\hline 15. & 1040 & 1313 & 237.77 & 372.30 & -74.30 & -0.009 & -0.137 \\
\hline 16. & 1050 & 1323 & 245.09 & 374.59 & -76.59 & -0.009 & -0.000 \\
\hline 17. & 1060 & 1333 & 252.59 & 376.93 & -78.93 & -0.009 & 0.1404 \\
\hline 18. & 1070 & 1343 & 260.25 & 379.33 & -81.33 & -0.010 & 0.284 \\
\hline 19. & 1080 & 1353 & 268.09 & 381.78 & -83.78 & -0.010 & 0.431 \\
\hline 20. & 1090 & 1363 & 276.11 & 384.28 & -86.28 & -0.010 & 0.581 \\
\hline 21. & 1100 & 1373 & 284.30 & 386.84 & -88.84 & -0.011 & 0.735 \\
\hline 22. & 1110 & 1383 & 292.67 & 389.46 & -91.46 & -0.011 & 0.892 \\
\hline 23. & 1120 & 1393 & 301.23 & 392.13 & -94.13 & -0.011 & 1.052 \\
\hline 24. & 1130 & 1403 & 309.97 & 394.87 & -96.87 & -0.012 & 1.217 \\
\hline 25. & 1140 & 1413 & 318.90 & 397.66 & -99.66 & -0.012 & 1.384 \\
\hline 26. & 1150 & 1423 & 328.03 & 400.51 & -102.51 & -0.012 & 1.555 \\
\hline 27. & 1160 & 1433 & 337.35 & 403.42 & -105.42 & -0.013 & 1.730 \\
\hline 28. & 1170 & 1443 & 346.86 & 406.39 & -108.39 & -0.013 & 1.908 \\
\hline 29. & 1180 & 1453 & 356.58 & 409.43 & -111.43 & -0.013 & 2.090 \\
\hline 30. & 1190 & 1463 & 366.50 & 412.53 & -114.53 & -0.014 & 2.276 \\
\hline 31. & 1200 & 1473 & 376.62 & 415.69 & -117.69 & -0.014 & 2.466 \\
\hline & & & & & & & \\
\hline
\end{tabular}

\section{The Pyrometer Calibration Response}

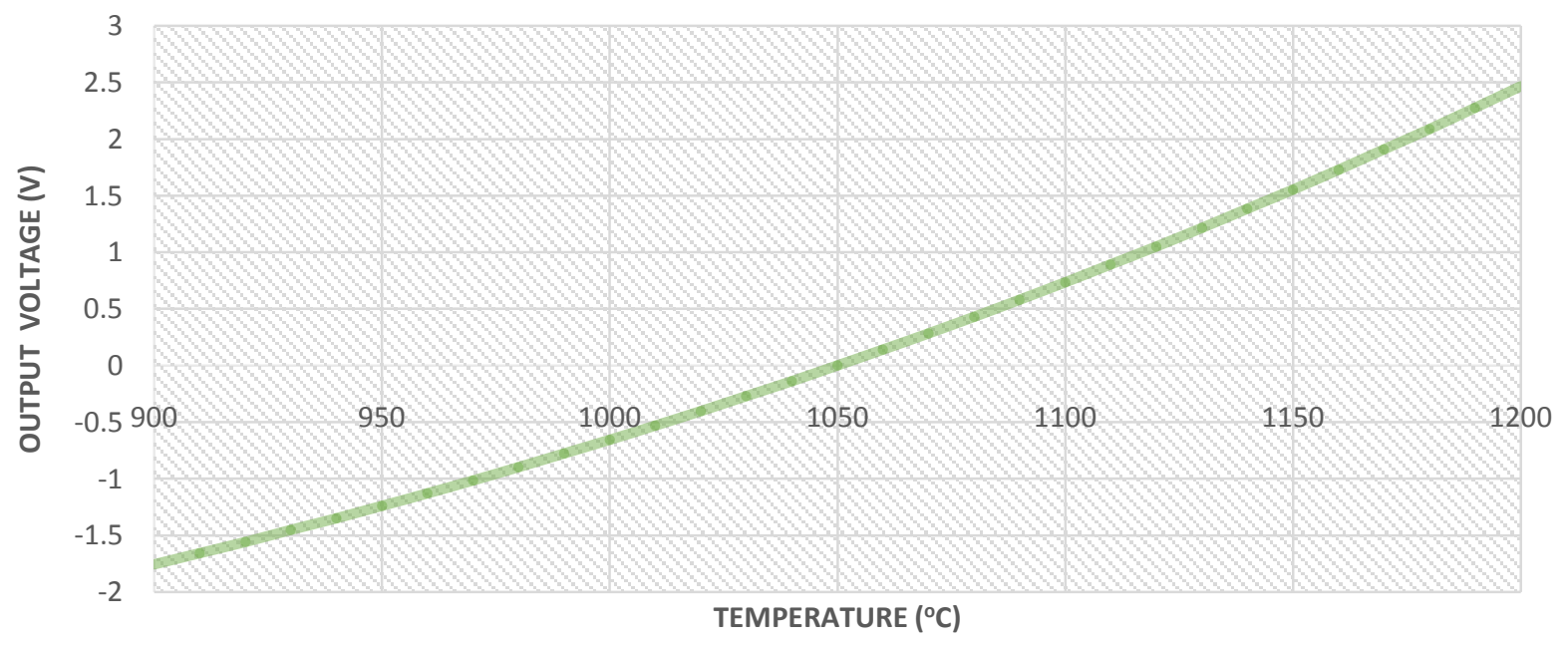

Fig 5 The Calibration Graph of Broadband Radiation Pyrometer Output Voltage (v) against Temperature $\left({ }^{\circ} \mathrm{C}\right)$ 


\section{The Pyrometer Calibration Response}

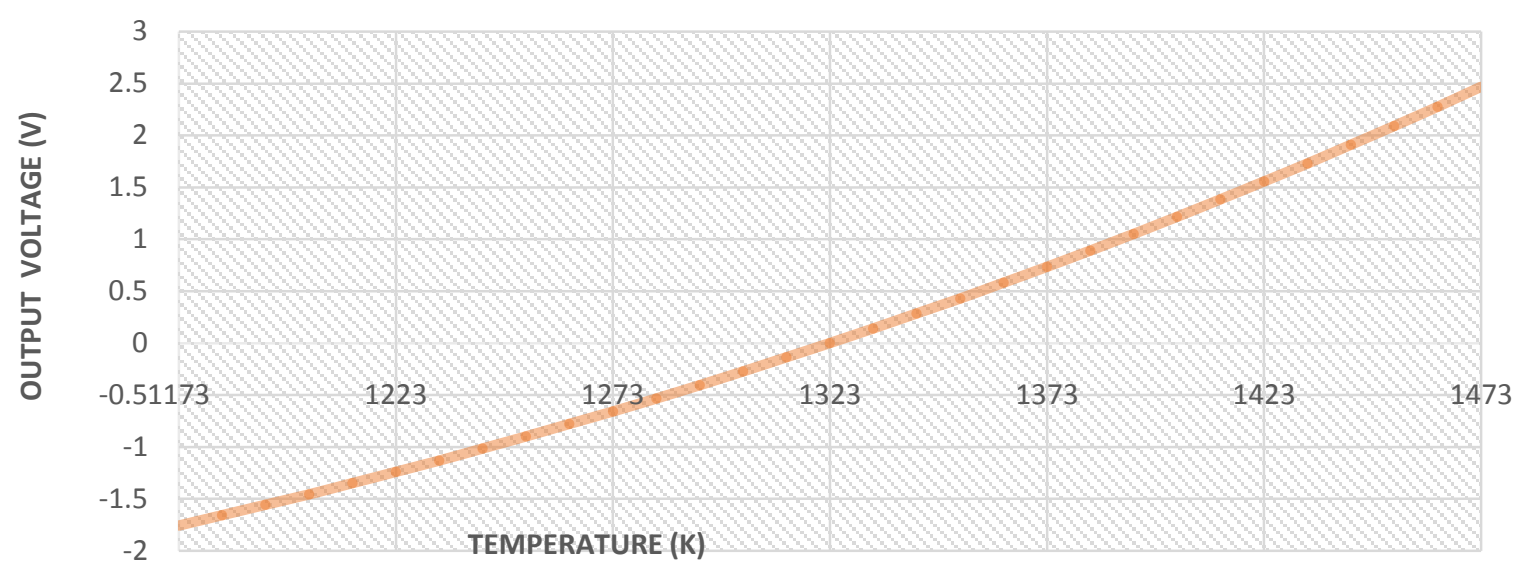

Fig 6: The calibration Graph of the Pyrometer Output Voltage (v) against Temperature (K).

\section{DISCUSSION AND IMPLEMENTATIONS}

\subsection{The Verification to ascertain the Pyrometer}

\section{Characteristics using Calibration Response}

The characteristics of the calibrated broadband Pyrometer design were verified to determine whether this design instrument meets conformity, sensitivity, and percent of its non-linearity as it is required.

\subsection{Test for the Design Instrument Conformity}

To calibrate a system, series of design stages are involved as shown in Table 1. Here, the graphical response will be compared with the design to establish the degree of the instrument's accuracy using its linearity, mid-temperature, and zero response.

\subsection{Instrument's Accuracy Based on Linearity}

At steady state, equation (4) was used to calibrate, and the analysis proves that it amounts to zero. Thus, equation (5) was further reduced to a linear function:

$$
T_{D}=\frac{1}{U A} P_{D}+T_{S}
$$

The linear function gives an intercept, $T_{S}$ on the vertical $\left(T_{D}\right)$ axis and a slope of $\frac{1}{U A}$. $T_{S}$ values are the absolute Kelvin temperature values of the surrounding. $P_{D}$ values are the detector total power values in watts, and it is plotted on the horizontal axis.

$$
\begin{gathered}
\text { Intercept on } \begin{array}{c}
T_{D} \text { axis }=T_{S}=25^{\circ} \mathrm{C}=(25+273) \mathrm{K} \\
=298 \mathrm{~K}
\end{array} \\
\text { Slope }=\frac{1}{U A}=\frac{1}{\left(2 \times 10^{4} \times 1.6 \times 10\right)^{-4}}=0.3125 \mathrm{~W}^{-1} \mathrm{C}
\end{gathered}
$$

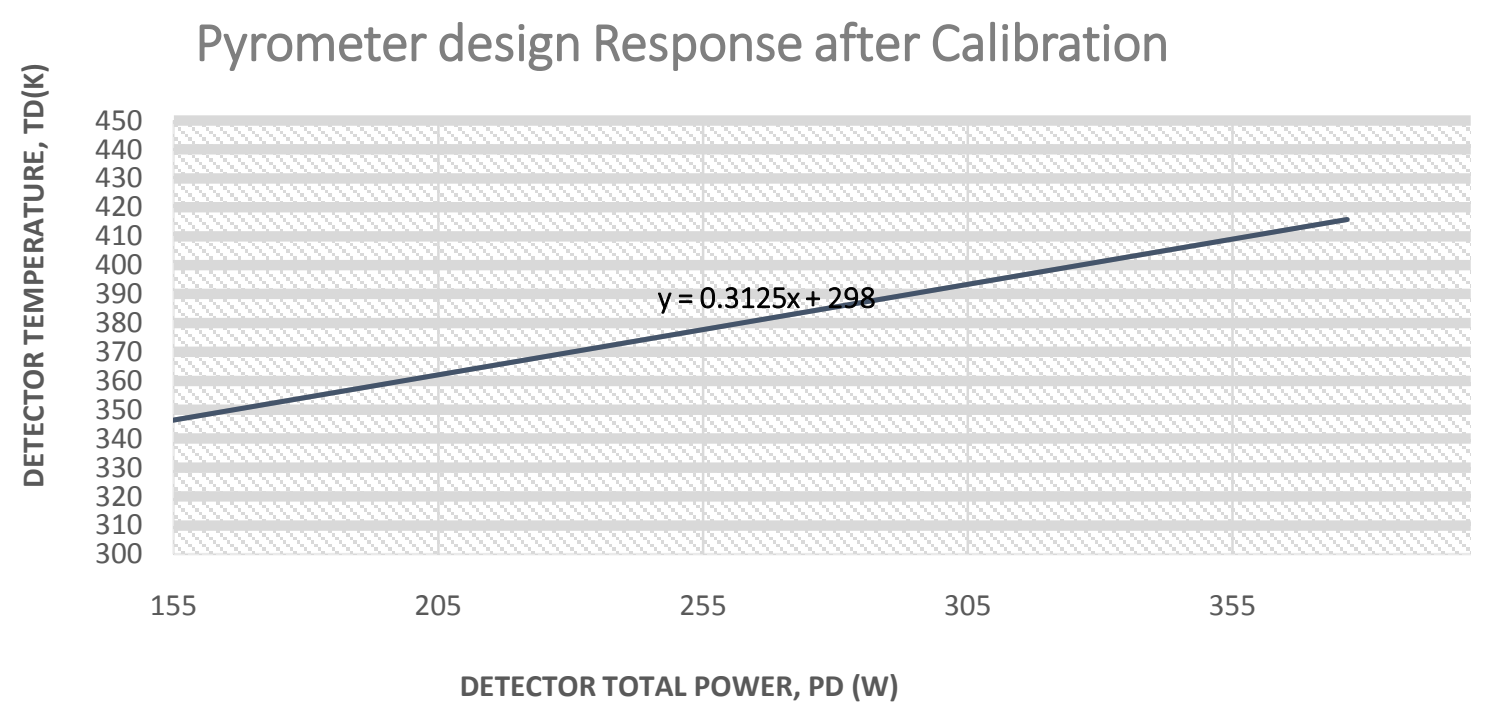

Fig 7 The Graph of Detector Temperature (K) against the Detector Total Power (W) 
Figure 7 illustrates the Linear Characteristics of Broadband Pyrometer at Steady State

The linear function: $y=0.3125 x+298$ is deduced from the graph:

$$
\begin{gathered}
\text { Sensitivity }=0.3125 \\
\text { Intercept on } y \text {-axis }=298 \mathrm{~K}
\end{gathered}
$$

With the available data from the graph of figure 7 , the design value proves its conformity. Thus, the calibration graph represents the behaviour of the Chopped Broadband Radiation Pyrometer.

\subsection{Instrument's Accuracy Based on Mid-Range}

\section{Temperature and Zero Response}

The design defined a zero output voltage for the Pyrometer at mid-range temperature $\left(\mathrm{T}_{\mathrm{D}}-\mathrm{T}_{\mathrm{S}}\right) ; \quad \mathrm{V}_{\text {OUT }}=0$ Volt. The mid-range temperature from Table 1 is $1050^{\circ} \mathrm{C}$ or $1323 \mathrm{~K}$ respectively. From the evidence in Figures 5 and 6 above, Mid-range Temperature $=1050^{\circ} \mathrm{C}$ and $1323 \mathrm{~K}$ is at 0 volt respectively. The graph agrees with the design. Conclusively this Pyrometer Calibration Graph represents the Characteristics of the Pyrometer and its performance.

\subsection{Test for Sensitivity Requirement}

The sensitivity of an instrument is the rate of change of the output of that instrument with respect to input changes.

$$
\text { Sensitivity, } S=\frac{\Delta \text { Output }}{\Delta \text { Input }}
$$

\section{The Pyrometer Response before calibration}

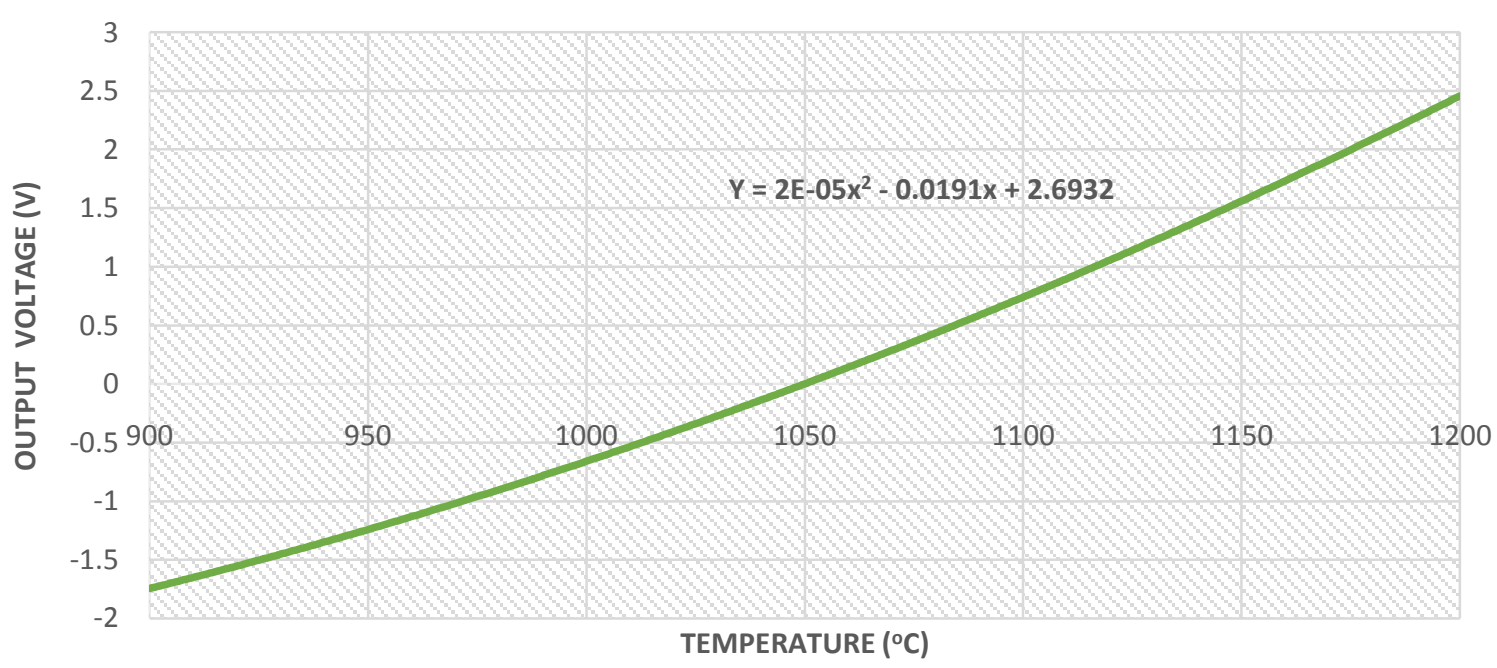

Fig 8. Graph of Output Voltage (v) against Temperature $\left({ }^{\circ} \mathrm{C}\right)$

Figure 8 illustrates the sensitivity Characteristics of Broadband Pyrometer. The result shows that the response is not linear as originally stated by the heat balance equation thus, this degree of non-linearity from this equation:

$$
y=0.00002 x^{2}-0.0191 x+2.6932
$$

Therefore to determine the sensitivity, a tangent line was drawn so that only the linear part was considered for the calculation. 


\section{The Pyrometer response after Calibration}

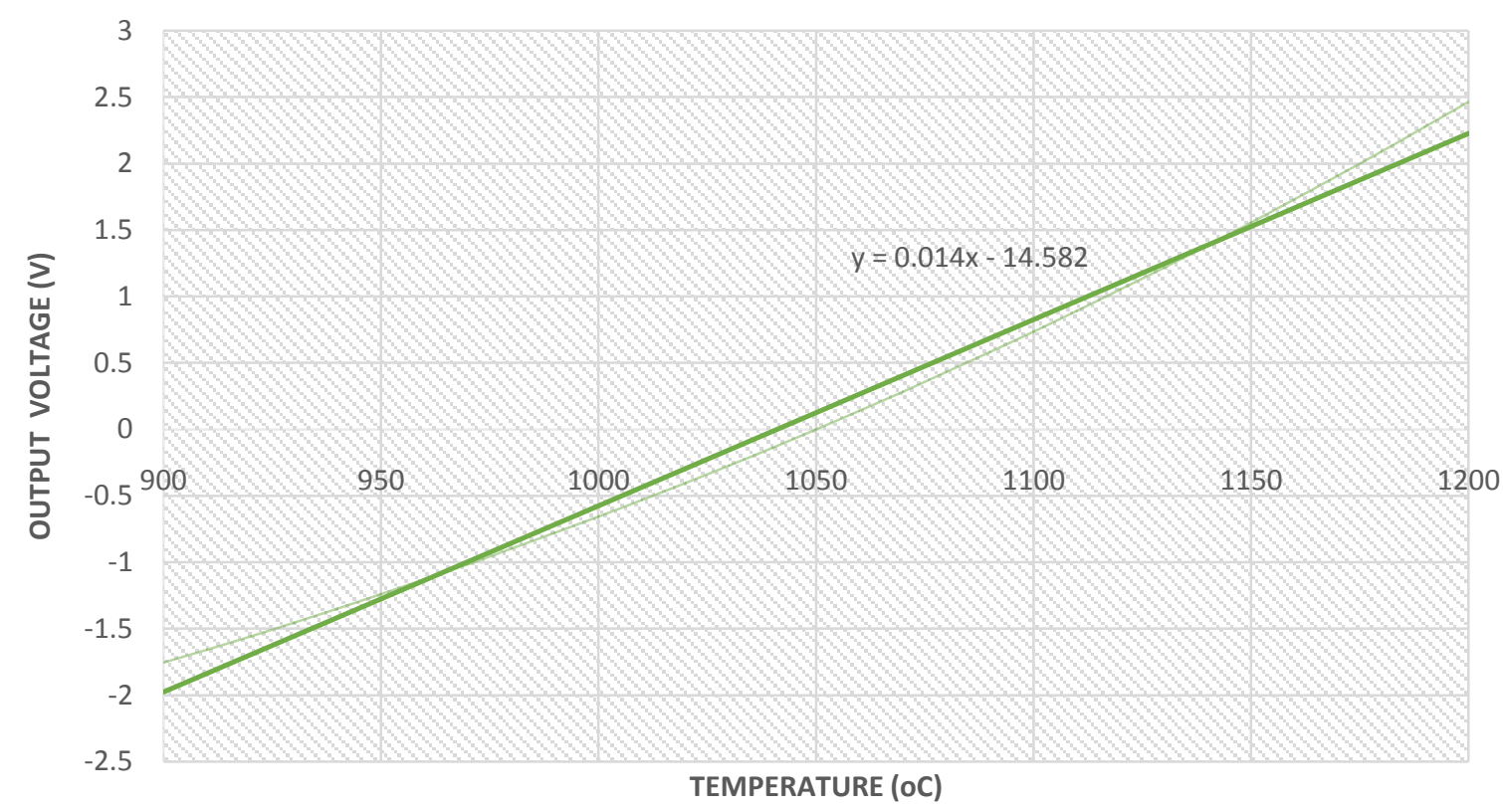

Fig 9 Graph of Output Voltage (v) against Temperature $\left({ }^{\circ} \mathrm{C}\right)$

Figure 9 illustrates the sensitivity Characteristics of Broadband Pyrometer. The equation defining the points of intersection of the two graphs, also defines the equation for determining the system's sensitivity:

$$
\begin{aligned}
y= & 0.014 x-14.582 \\
\therefore \text { Sensitivity, } S & =\frac{d y}{d x}=\frac{d(0.014 x-14.582)}{d x} \\
& =0.014 V^{\circ} \mathrm{C}^{-1} d
\end{aligned}
$$

\subsection{Test for Percent Non-Linearity Requirement}

The theory has it that for a system to be linear the input, and the output quantities must be proportional. Therefore, the linearity of a system is the closeness of the calibration curve of a measuring system to a straight line.

The non-linearity is therefore determined as the departure from the linear value and expressed in percent:

$$
\% \text { non }- \text { linearity }=\frac{\text { Maximum Deviation }}{\text { Output Span }} \times 100 \%
$$

\section{The Pyrometer Calibration Response}

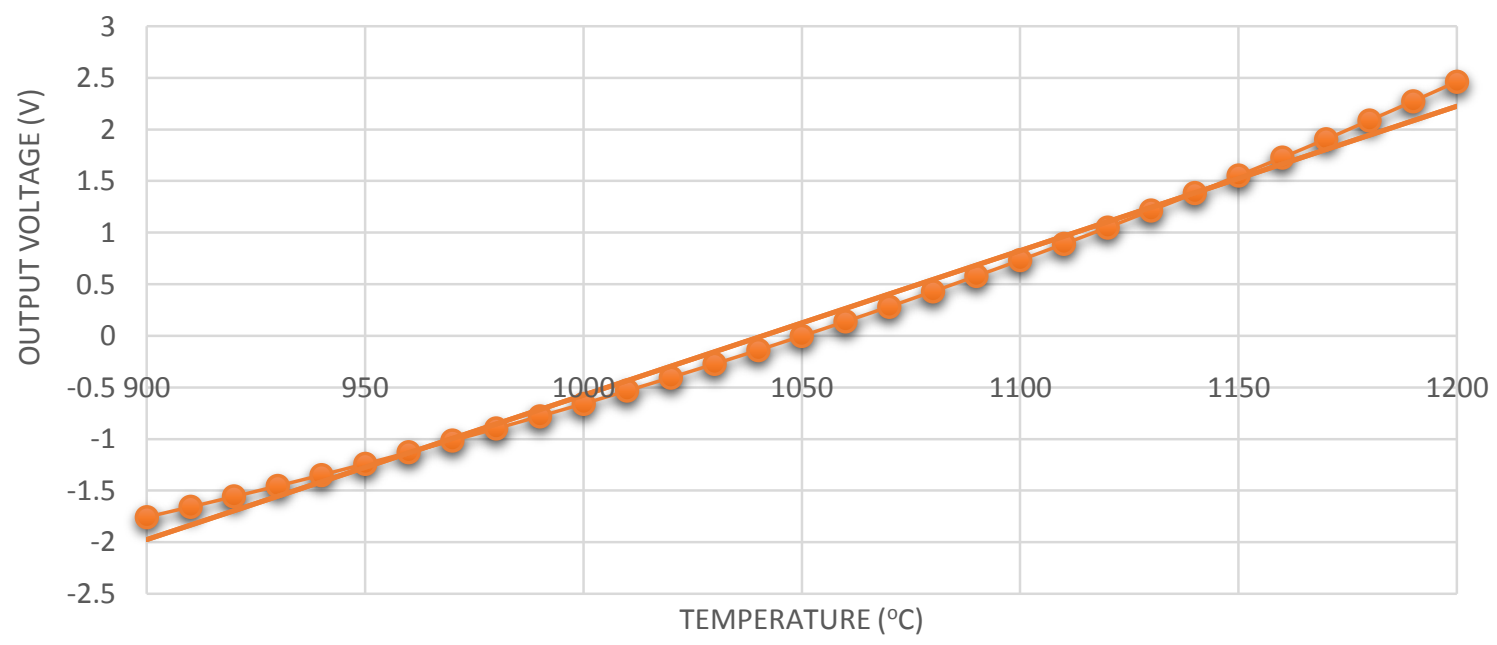

Fig 10. The Graph of Output Voltage (v) against Temperature(C) 
Figure 10 illustrates the characteristics of the designed Chopped Broadband Radiation Pyrometer. The dotted line represents the actual nonlinear response while the straight line represents the linear response after calibration. The coordinates are intersected from the graph of figure 10, thus the Maximum Deviation (extracted from the graph) = $0.1015 \mathrm{~V}$

And the Output Span $=1.5551775-(-1.2396225)=2.7948 \mathrm{~V}$

$$
\therefore \% \text { non }- \text { linearity }=\frac{0.1015}{2.7948} \times 100 \%=3.6317 \%
$$

Conclusively, the Pyrometer is moderately linear with a tolerable non-linearity of $3.6 \%$.

\section{CONCLUSION}

The signal conditioning and data acquisition elements were thus designed. These elements were meant for a chopped broadband radiation pyrometer capable of measuring a range of temperature from $900^{\circ} \mathrm{C}$ to $1200^{\circ} \mathrm{C}$. The successful achievement of this work gave the following parameters: temperature measured: $900^{\circ} \mathrm{C}$ to $1200^{\circ} \mathrm{C}(1173 \mathrm{~K}$ to $1473 \mathrm{~K}$ respectively); the calibrated instrument is relatively linear with a tolerable non-linearity of $3.6 \%$; with the sensitivity of $0.014 V^{\circ} \mathrm{C}^{-1}$. The resolution was quite very small; as such the instrument so designed easily detects the slightest change at its input. The rotating shutter was configured to supply the chopped signal. It operates at a frequency of $50 \mathrm{~Hz}$ that was found to be lower than the system frequency of $200 \mathrm{~Hz}$. The data acquisition system was able to capture data at a periodic time of 0.02 second and below thus, the system operates within the specified sampling range satisfying Nyquist criteria.

\section{REFERENCES}

[1] Alan S. M. (2001) Measurement and Instrumentation Principles, Third Edition, Butterworth-Heinemann, UK.

[2] Bentley, J. P. (2005) Principles of Measurement Systems, Fourth Ed., Prentice Hall, USA.

[3] Bowden, F. P. and Thomas, P. H. (1954). The Surface Temperature of Sliding Solids. Proc Roy Soc London.

[4] Jones, T. P., Gardner, J. L., \& Richards, A. J. (1987). Radiation Pyrometers for Temperature Measurement during Aluminum Processing. Journal of Physics E: Scientific Instruments, 20(6), 615.

[5] Komanduri, R., \& Hou, Z. (2001).A Review of the Experimental Techniques for the Measurement of Heat and Temperatures Generated in some Manufacturing Processes and Tribology. Tribology International, 34(2001), 653 - 682.

[6] Orlov, I. Y., Nikiforov, I. A. \& Afanasjev, A. V. (2014). Wireless Infrared Pyrometer with Fiber Optic: Construction and Processing Algorithms. Wireless Engineering and Technology, 5, 25 - 33 .

[7] Ramos, M., de Pablo, M. A., Sebastian, E., Armiens, C. \& Gomez-Elvira, J. (2012).Temperature Gradient
Distribution in Permafrost Active Layer, Using a Prototype of the Ground Temperature Sensor (RemsMsl) on Deception Island (Antarctica). Cold Regions Science and Technology, 72, $23-32$.

[8] Thomas A. H. (2006) Measurement and Control Basics, Fourth Ed. Heywood \& Company Ltd., London.

[9] Webster, J. G. (1999). The Measurement, Instrumentation and Sensors Handbook. CRC Press in corporation with IEEE Press, California, USA. 